\title{
Volume of Distribution of Fraction Dose Predicted Normalized by Weight
}

National Cancer Institute

\section{Source}

National Cancer Institute. Volume of Distribution of Fraction Dose Predicted Normalized by Weight. NCI Thesaurus. Code C92430.

The predicted volume of distribution of the absorbed fraction associated with the terminal slope following extravascular administration, where F equals the fraction of dose absorbed, divided by the weight. 